\title{
Verbos Auxiliares e Locuções Verbais: descrição e análise comparada do português, do francês $e$ do inglês
}

\begin{abstract}
Auxiliary Verbs and Verbal Phrases: Description and comparative analysis of Portuguese, French, ANd English
\end{abstract}

\section{Gustavo Lopez ESTIVALET*}

Resumo: Este trabalho apresenta de forma objetiva e estruturada a utilização dos principais verbos auxiliares e sua aplicação em locuções verbais no português, no francês e no inglês. Os verbos auxiliares possuem um importante papel na modulação do aspecto nos tempos compostos. Eles permitem a construção de locuções verbais complexas capazes de relativizar o tempo e o aspecto dos eventos descritos pelo verbo principal. A utilização de verbos auxiliares nas diferentes línguas possui semelhanças e paralelos, mas também distinções definidas diacronicamente e gramaticalmente. Sendo assim, este estudo faz uma descrição detalhada dos principais verbos auxiliares nas três línguas citadas, utilizando conceitos e definições da literatura. Em seguida, este trabalho realiza uma análise da utilização dos diferentes verbos auxiliares através de exemplos e equivalências entre as línguas pesquisadas. Enfim, os verbos auxiliares, tempos compostos e locuções verbais no português, francês e inglês são discutidos de forma comparada. A partir deste estudo, obtém-se uma melhor compreensão da modulação predicativa através de proposições verbais complexas.

\footnotetext{
* Pós-doutorando (PDJ/CNPq) no Laboratório da Linguagem e Processos Cognitivos (LabLing) da Universidade Federal de Santa Catarina (UFSC). Doutorado (2016) na École Doctorale Neurosciences et Cognition (NSCo) da Université Claude Bernard Lyon 1 (UCBL) no Laboratoire sur le Langage, le Cerveau et la Cognition (L2C2), Lyon, França. Mestrado (2012) em Linguística na UFSC. Contato: gustavoestivalet@hotmail.com.
} 
Palavras-chave: Verbos auxiliares. Locuções verbais. Tempos compostos.

Abstract: This paper presents in an objective and structured way the use of the main auxiliary verbs and their application in verbal phrases in Portuguese, French, and English. Auxiliary verbs play an important role in the modulation of aspect in compound tenses. They allow the construction of complex verbal phrases which can relativize the aspect and tense of the events described by the main verb. The use of the auxiliary verbs has many similarities and parallels in the different languages, but also distinctions which are diachronically and grammatically defined. Therefore, this study makes a detailed description of the main auxiliary verbs from the three languages mentioned, using concepts and definitions from the literature. Then, this paper performs an analysis of the use of the different auxiliary verbs by examples and equivalences among the languages. Finally, the auxiliary verbs, compound tenses, and verbal phrases in Portuguese, French, and English are discussed in a comparative way among these languages. From this study, we can have a better understanding of the predicative modulation in complex verbal propositions. Keywords: Auxiliary verbs. Verbal phrases. Compound tenses.

\section{Introdução}

Os verbos auxiliares desempenham um papel extremamente importante na articulação e modulação dos tempos verbais compostos, enriquecendo cada língua de forma diferente e específica (ARNAULD; LANCELOT, 1992). Este trabalho tem o objetivo de realizar uma descrição comparada dos verbos auxiliares através da compreensão do seu desenvolvimento e sua utilização em três línguas diferentes: português, francês e inglês. Primeiramente, serão abordadas as definições gramaticais desses conceitos; em seguida, serão apresentadas suas utilizações e seu emprego; para finalizar, será realizada uma análise comparativa de exemplos das três línguas. Ainda, este trabalho discorrerá sobre os tempos compostos, locuções verbais e conjugações perifrásticas.

Conforme Pontes (1973), as locuções verbais criadas pelos verbos auxiliares constituem potencialmente sua conjugação completa e nascem da 
necessidade de expressão complexa para a expressão do aspecto verbal. Observa-se que todos os tempos compostos gerados pelos verbos auxiliares originaram-se de um traço semântico comum e "fora do quadro das formas simples, aliviando-se assim o paradigma geral dos complicados ingredientes de tempos perfeitos compostos e tempos anteriores, passados e exatos. Trata-se de uma conjugação perifrástica” (ALI, 1964, p. 19). Destaca-se que a principal dicotomia estabelecida no aspecto verbal é em relação ao aspecto perfeito e imperfeito, isto é, entre eventos acabados e eventos não acabados (e.g., João comeu o bolo; João comia o bolo).

Apesar dos diversos verbos auxiliares citados nas gramáticas das diferentes línguas, os verbos "ter" e "ser" - equivalentes aos verbos "avoir" e "être" do francês, e aos verbos "to be" e "to have" do inglês - são, sem dúvidas, os verbos auxiliares por excelência, apresentando diferentes funções específicas nas diversas línguas (ALMEIDA, 1963; ALI, 1964; PALMER, 1974; BAYLON; FABRE, 1995). Em relação às distintas línguas, poder-se-ia acrescentar os verbos "haver" e "estar" do português (CUNHA; CINTRA, 1985), o verbo "to do" do inglês (MURPHY, 1990) e a partícula " $y$ " associada ao verbo "avoir" do francês (DUBOIS, 1967). Apesar de muitas vezes serem apresentados de forma diferente pelas gramáticas, elas admitem o verbo auxiliar como o pivô central na articulação dos tempos compostos e das locuções verbais. As locuções verbais surgiram e se desenvolveram com o intuito de definir, especificar e enriquecer sentenças complexas no que diz respeito ao tempo, mas, principalmente, para uma maior especificação do aspecto da sentença (ARNAULD; LANCELOT, 1992). Fernandes, Luft e Guimarães (1993) definem "aspecto" como a maneira pela qual uma coisa se apresenta, aparenta, principalmente, do lado exterior, a partir de um ponto de vista.

Nesse sentido, "os conjuntos formados de um verbo auxiliar com um verbo principal chamam-se locuções verbais. Nas locuções verbais conjuga-se apenas o auxiliar, pois o verbo principal vem sempre numa das formas nominais: no particípio, no gerúndio, ou no infinitivo pessoal" (CUNHA; CINTRA, 1985, p. 383). As locuções verbais são sentenças com dois ou mais verbos que exprimem ações complexas e específicas em relação ao tempo e ao aspecto. Para tanto, utilizam-se os diferentes verbos auxiliares seguidos das três formas nominais: infinitivo, gerúndio e particípio. Elas são 
chamadas de formas nominais porque podem assumir o comportamento de substantivos, adjetivos e advérbios em determinadas circunstâncias (INFANTE, 2004).

Numa perspectiva sincrônica, Beard (1995) argumenta que os verbos auxiliares possuem um papel gramatical na construção dos tempos compostos, agregando complexidade aspectual e relatividade temporal. Portanto, os tempos compostos possuem diferenças significativas de estrutura e de aplicação em relação às locuções verbais, pois as locuções verbais apresentam maior liberdade na descrição do predicado complexo.

Assim, a seção a seguir apresenta, de forma objetiva e organizada, os verbos auxiliares, os tempos compostos e as locuções verbais do português, do francês e do inglês, por meio da apresentação de seus paradigmas. $\mathrm{Na}$ seção seguinte, descreve-se a utilização dos verbos auxiliares, dos tempos compostos e das locuções verbais através de exemplos e comparações entre as línguas. Depois, discute-se a complexidade predicativa da modulação aspectual e da relatividade temporal nas perífrases verbais.

\section{Verbos Auxiliares, Tempos Compostos e Locuções Verbais}

Com o objetivo de se observar claramente os verbos auxiliares nas três línguas de interesse desse trabalho - português, francês e inglês -, apresenta-se, na Tabela 1, a conjugação dos principais verbos auxiliares no tempo presente do indicativo.

Tabela 1 - Verbos auxiliares "ter", "ser", "haver" e "estar" do português; "avoir" 'ter' e "être" 'ser/estar' do francês; "to be" 'ser/estar' "to have" 'ter' e "to do" do inglês, conjugados no presente do indicativo

\begin{tabular}{|c|c|c|c|c|c|c|c|c|c|}
\hline \multicolumn{2}{|c|}{ Português ter } & \multirow{2}{*}{$\begin{array}{l}\text { ser } \\
\text { sou }\end{array}$} & \multirow{2}{*}{$\begin{array}{l}\text { haver } \\
\text { hei }\end{array}$} & \multirow{2}{*}{$\begin{array}{l}\text { estar } \\
\text { estou }\end{array}$} & \multirow{2}{*}{$\begin{array}{l}\text { Francês } \\
\mathrm{je} / \mathrm{j}^{\prime}\end{array}$} & avoir être & \multirow{2}{*}{$\begin{array}{l}\text { Inglês } \\
\text { I }\end{array}$} & \multicolumn{2}{|c|}{ to beto haveto do } \\
\hline eu & tenho & & & & & ai & & am have & do \\
\hline $\mathbf{u}$ & tens & és & hás & estás & tu & as & & are hav & do \\
\hline le/ela & tem & é & há & está & $\mathrm{il} / \mathrm{e}$ & est & , & has & doe \\
\hline oós & & & & & & avons so & & are have & do \\
\hline ós & tendes & s sois & & estais & & avez êtes & & are have & do \\
\hline les/elas & têm & são & hão & estão & ils/elles & ont sont & they & are have & do \\
\hline
\end{tabular}

Fonte: Elaborada pelo autor. 
Em relação às equivalências dos tempos verbais entre as diferentes línguas, enquanto o tempo simples pretérito perfeito do indicativo do português é utilizado normalmente para descrever eventos de aspecto finito no passado (e.g., eu cantei), o tempo simples passé simple do francês é utilizado exclusivamente na literatura e na escrita formal do francês, com raras ocorrências orais (e.g., je chantai 'eu cantei') (DUBOIS, 1967). O tempo composto passé composé do francês, formado pelo verbo "avoir" ou "être" conjugado no présent de l'indicatif seguido do participe passé do verbo principal (e.g., j'ai chanté 'eu cantei'; je suis monté 'eu subi'), se consolidou oralmente, substituindo o passé simple e sendo utilizado com a mesma função do pretérito perfeito do português e do simple present do inglês (ESTIVALET; MARGOTTI, 2014). Contudo, observa-se no francês uma diferença de aspecto entre a utilização do passé simple e do passé composé em textos escritos, principalmente em textos históricos e na literatura (BESCHERELLE, 2006b). Enquanto o tempo simples passé simple é utilizado para descrever eventos completamente terminados no passado, o tempo composto passé composé é utilizado para descrever eventos que começaram no passado, mas ainda não terminaram ou possuem consequências no presente (BAYLON; FABRE, 1995). Esta última utilização do passé composé do francês é semelhante à utilização do present perfect do inglês, formado pelo verbo "to have" conjugado no presente seguido do past participle do verbo principal (e.g., I have sung 'eu cantei') (CELCE-MURCIA; LARSEN-FREEMAN, 1999).

Conforme o passé composé do francês e o present perfect do inglês, o tempo verbal pretérito perfeito composto do indicativo do português também é formado pelo verbo "ter" conjugado no presente do indicativo seguido do particípio passado do verbo principal (e.g., eu tenho cantado) (ALI, 1964). Entretanto, sua utilização é diferente, ele descreve um evento repetitivo que começou no passado e se repete até o presente (INFANTE, 2004). Além do aspecto do inglês de algo que se desenrola do passado até o presente, esse tempo verbal composto apresenta aspecto repetitivo, iterativo e imperfectivo. Enquanto no português e no francês essas conjugações são chamadas de "passados" compostos, no inglês ele é chamado de "presente" perfeito (MURPHY, 1990). Extrapolando-se os limites da conjugação do verbo auxiliar no tempo presente do indicativo, outros diversos tempos compostos são formados a partir da conjugação do verbo auxiliar nos tempos 
simples seguidos do particípio passado do verbo principal (Anexo A). Na Tabela 2, são listados os tempos verbais compostos do português, do francês e do inglês.

Tabela 2 - Tempos compostos, tempo de conjugação dos verbos auxiliares e exemplos do português, francês e inglês.

\begin{tabular}{|c|c|c|c|c|c|c|c|c|}
\hline \multicolumn{3}{|l|}{ Português } & \multicolumn{3}{|l|}{ Francês } & \multicolumn{3}{|l|}{ Inglês } \\
\hline Indicativo & $\begin{array}{l}\text { Tempo do } \\
\text { verbo } \\
\text { auxiliar }\end{array}$ & $\begin{array}{l}\text { ter } \\
1 \mathrm{~s}\end{array}$ & Indicatif & $\begin{array}{l}\text { Tempo do } \\
\text { verbo } \\
\text { auxiliar }\end{array}$ & $\begin{array}{l}\text { avoir } \\
1 \mathrm{~s}\end{array}$ & Indicative & $\begin{array}{l}\text { Tempo } \\
\text { do verbo } \\
\text { auxiliar }\end{array}$ & $\begin{array}{l}\text { to } \\
\text { have/ } \\
\text { to will } \\
\text { 1s }\end{array}$ \\
\hline $\begin{array}{l}\text { pretérito } \\
\text { perfeito } \\
\text { composto }\end{array}$ & presente & tenho & $\begin{array}{l}\text { passé } \\
\text { composé }\end{array}$ & présent & ai & $\begin{array}{l}\text { present } \\
\text { perfect }\end{array}$ & $\begin{array}{l}\text { simple } \\
\text { present }\end{array}$ & have \\
\hline \multirow[t]{2}{*}{$\begin{array}{l}\text { pretérito } \\
\text { mais-que- } \\
\text { perfeito } \\
\text { composto }\end{array}$} & $\begin{array}{l}\text { pretérito } \\
\text { imperfeito }\end{array}$ & tinha & $\begin{array}{l}\text { plus-que- } \\
\text { parfait }\end{array}$ & imparfait & avais & $\begin{array}{l}\text { past } \\
\text { perfect }\end{array}$ & $\begin{array}{l}\text { simple } \\
\text { past }\end{array}$ & had \\
\hline & & & $\begin{array}{l}\text { passé } \\
\text { antérieur }\end{array}$ & passé simple & eus & & & \\
\hline $\begin{array}{l}\text { futuro do } \\
\text { presente } \\
\text { composto }\end{array}$ & futuro & terei & $\begin{array}{l}\text { future } \\
\text { antérieur }\end{array}$ & futur & aurai & $\begin{array}{l}\text { future } \\
\mathrm{i}\end{array}$ & $\begin{array}{l}\text { simple } \\
\text { present }\end{array}$ & will \\
\hline $\begin{array}{l}\text { futuro do } \\
\text { pretérito } \\
\text { composto }\end{array}$ & $\begin{array}{l}\text { futuro do } \\
\text { pretérito }\end{array}$ & teria & $\begin{array}{l}\text { passé du } \\
\text { conditionnel }\end{array}$ & $\begin{array}{l}\text { présent du } \\
\text { conditionnel }\end{array}$ & aurais & $\begin{array}{l}\text { future } \\
\text { ii }\end{array}$ & & $\begin{array}{l}\text { will } \\
\text { have }\end{array}$ \\
\hline \multicolumn{9}{|l|}{ Subjuntivo } \\
\hline $\begin{array}{l}\text { pretérito } \\
\text { perfeito } \\
\text { composto }\end{array}$ & presente & tenha & passé & présent & aie & $\begin{array}{l}\text { conditional } \\
\mathrm{i}\end{array}$ & $\begin{array}{l}\text { simple } \\
\text { past }\end{array}$ & would \\
\hline $\begin{array}{l}\text { pretérito } \\
\text { mais-que- } \\
\text { perfeito } \\
\text { composto }\end{array}$ & $\begin{array}{l}\text { pretérito } \\
\text { imperfeito }\end{array}$ & tivesse & $\begin{array}{l}\text { plus-que- } \\
\text { parfait }\end{array}$ & imparfait & eusse & $\begin{array}{l}\text { conditional } \\
\text { ii }\end{array}$ & $\begin{array}{l}\text { simple } \\
\text { present/ } \\
\text { past }\end{array}$ & $\begin{array}{l}\text { would } \\
\text { have }\end{array}$ \\
\hline $\begin{array}{l}\text { futuro } \\
\text { composto }\end{array}$ & futuro & tiver & & & & & & \\
\hline
\end{tabular}

Fonte: Elaborado pelo autor.

No português, o verbo auxiliar "ter" pode se ligar ao infinitivo do verbo principal através da preposição “de” (e.g., eu tenho de cantar), indicando necessidade, dever e obrigação (CUNHA; CINTRA, 1985). Já o verbo auxiliar "ser" seguido do particípio passado caracteriza a voz passiva (e.g., a música foi cantada) (ANDRÉ, 1990). Este último também pode se ligar ao infinitivo através da preposição "de" (e.g., eu sou de cantar), indicando maneira, forma e hábito (VILLALVA, 1994). Já o verbo auxiliar "estar" é utilizado com o gerúndio do verbo principal para formar os tempos progressivos (e.g., eu 
estou cantando), criando locuções verbais que designam atos duradouros e eventos em acontecimento. Essa construção é exatamente igual ao present continuous do inglês (e.g., I am singing 'eu estou cantando') e apresenta aspecto imperfectivo da ação que acontece durante o ato de fala (BUENO, 1996). Destaca-se que o francês não utiliza essa locução verbal, nem tempos progressivos, empregando simplesmente o présent para descrever eventos em acontecimento (e.g., je chante 'eu canto'). No francês, o gerúndio é utilizado somente para descrever eventos secundários como plano de fundo de um evento principal (e.g., je mange en regardant la télé 'eu como olhando TV') (ESTIVALET; MARGOT'TI, 2014). Ainda em relação ao português, o verbo auxiliar "ser" combina-se também com o infinitivo impessoal mediante as preposições “a”, "por" e "para” (e.g., eu estou a cantar, eu estou por cantar, eu estou para cantar). O primeiro caso indica o mesmo que a locução verbal "estar" + gerúndio (tipicamente no português europeu); o segundo caso indica uma ação que deve ou deveria realizar-se; e o último caso exprime a iminência do acontecimento do evento (INFANTE, 2004).

Em relação às formas nominais, o particípio passado é a forma nominal que participa ao mesmo tempo da natureza do verbo e do adjetivo (VILLALVA, 1994). Sua natureza verbal se manifesta nas locuções verbais, nos tempos compostos e em orações reduzidas. A maior parte dos particípios passados são formas regulares formadas a partir do tema (radical + vogal temática) concatenado ao sufixo do particípio passado. Por exemplo, no português com o sufixo [-do] (e.g., am[a][do], com[i][do], dorm[i][do]), com neutralização da vogal temática dos $2^{\circ}$ e $3^{\circ}$ grupos em [-i-] (ROCHA, 1999); no francês com o sufixo [-é] para o $1^{\circ}$ grupo (e.g., parl[é] 'falado') e nulo para o $2^{\circ}$ grupo (e.g., fini 'terminado') (TOURATIER, 1996); em inglês com o sufixo [-ed] em verbos regulares (e.g., play[ed] 'jogado'), que por sua vez, é o mesmo sufixo do tempo verbal simple past (BYBEE, 1995). Nos verbos irregulares do inglês, alguns verbos do $2^{\circ}$ e $3^{\circ}$ grupos do português e nos verbos do $3^{\circ}$ grupo do francês, observa-se a existência de particípios passados irregulares (e.g., inglês: take/taken, sing/sung; português: dizer/dito, abrir/aberto; francês: boire/bu, ouvrir/ouvert) (BEARD, 1995). O português ainda possui os verbos abundantes que apresentam mais de uma forma de particípio passado, normalmente determinado de acordo com o verbo auxiliar utilizado na locução verbal (PONTES, 1973). Assim, além das formas regulares em [-do] utilizadas com os verbos auxiliares "ter" e "haver", surgem 
as chamadas formas curtas utilizadas com os verbos auxiliares "ser" e "estar" (e.g., ele tem entregado/ele foi entregue, ele tinha morrido/ele está morto).

O inglês não possui morfema de acordo de gênero e/ou número nos past participles (e.g., she has traveled 'ela tem viajado', they have traveled 'eles têm viajado') (RICHARDS, 2005). Já o português não realiza acordo de gênero e número com o sujeito ou com o objeto direto quando o particípio passado é utilizado nos tempos compostos, mas realiza o acordo com o sujeito quando o particípio passado é utilizado na forma nominal ou locuções verbais passivas (e.g., elas têm viaja[do], elas são viaja[das], elas são ensina[das] pelo professor) (HOUAISS; VILLAR, 2009). No francês, assim como no português, o participe passé concorda com o sujeito quando utilizado na forma adjetiva, mas, principalmente, ele concorda com o sujeito quando utilizado na forma verbal ligada ao verbo auxiliar "être" (e.g., elles sont arriv [ées] 'elas chegaram'). Interessante, no francês o participe passé também concorda com o complemento objeto direto quando o complemento é anterior ao verbo principal (e.g., les filles, il les a aim [ées] 'as meninas, ele as adorou) (EMONDS, 1978; BONET, 2013).

O infinitivo (infinitivo impessoal do português) apresenta o processo verbal em si mesmo, sem nenhuma noção de tempo, modo ou acordo (e.g., português: canta $[\mathrm{r}]$, come $[\mathrm{r}]$, dormi $[\mathrm{r}]$; francês: chante $[r]$, fini $[r]$, boi $[r e]$; inglês: to play, to sing). O gerúndio indica um evento em acontecimento, podendo desempenhar as funções de advérbio ou adjetivo (MARGOT'TI, 2008). Ele é realizado através do morfema [-ndo] no português (e.g., ama[ndo], come[ndo], dormi[ndo]), do morfema [-ant] no francês precedido pela preposição "en" (e.g., en aim [ant], en finiss[ant], en buv[ant]) e do morfema [-ing] no inglês (e.g., play[ing], sing[ing]), conforme apresentado na Tabela 3.

Tabela 3 - Formas nominais: infinitivo, gerúndio e particípio passado do português, francês e inglês.

\begin{tabular}{|c|c|c|c|c|c|c|c|c|}
\hline Nominais & Portuguê & & & Francês & & & Inglês & \\
\hline $\begin{array}{l}\text { Infinitivo } \\
\text { impessoal }\end{array}$ & cantar & comer & dormir & chanter & finir & boire & to play & to sing \\
\hline Gerúndio & cantando & comendo & dormindo & $\begin{array}{l}\text { en } \\
\text { chantant }\end{array}$ & $\begin{array}{l}\text { en } \\
\text { finissant }\end{array}$ & $\begin{array}{l}\text { en } \\
\text { buvant }\end{array}$ & playing & singing \\
\hline $\begin{array}{l}\text { Particípio } \\
\text { passado }\end{array}$ & cantado & comido & dormido & chanté & fini & bu & played & sung \\
\hline
\end{tabular}

Fonte: Elaborada pelo autor. 
Enfim, o verbo é a palavra que se flexiona em número, pessoa, modo e tempo para indicar ação (correr, pular), estado ou mudança de estado (ser, ficar), fenômeno natural (chover, anoitecer), ocorrência (acontecer, suceder), desejo (querer, aspirar) e outros processos mais específicos (ALI, 1964; TOURATIER, 1996; INFANTE, 2004), sendo representado nas formas verbais flexionadas e nominais. Quando há necessidade de se expressarem tempos verbais e aspectos verbais complexos, usam-se os verbos auxiliares para a formação dos tempos compostos. Ainda, os verbos auxiliares desempenham uma função fundamental nas locuções verbais, sendo capazes de criar predicados complexos no que diz respeito ao tempo e ao aspecto (e.g., ele tem ido dormir cedo, ele está indo dormir cedo; il est allé dormir tôt 'ele foi dormir cedo', il va aller dormir tôt 'ele vai ir dormir cedo'; he was going to sleep early 'ele estava indo dormir cedo', he will have gone to sleep early 'ele vai ter ido dormir cedo') (DUBOIS, 1967; CUNHA; CINTRA, 1985; BEARD, 1995).

\section{Utilização dos Verbos Auxiliares e das Locuções Verbais}

Observa-se nas gramáticas normativas a falta de concordância entre os autores dos termos empregados referentes aos verbos auxiliares e locuções verbais, resultando na utilização de termos idênticos, mas definidos de forma diferente. Por exemplo, enquanto alguns autores designam a locução verbal como qualquer sequência verbal com coesão interna de modo que funcione como um verbo simples, outros autores classificam as locuções verbais contendo tempos compostos como sequências verbais especiais. Dentre essas diferentes definições, o termo locução verbal se apresenta como sinônimo de conjugação perifrástica (FARACO; MOURA, 1999).

Retornando-se às origens dessas definições, observa-se que, na evolução do português, quando não era encontrada a forma sintética correspondente à forma latina, desenvolveram-se formas compostas com sequências verbais (PONTES, 1973). Por exemplo, enquanto o latim possuía uma forma simples passiva, o português e o francês incorporaram rodeios ao verbo principal com o objetivo de exprimir o aspecto original do latim, como as sequências formadas pelos verbos auxiliares "ser" e "ter" seguido do particípio passado do verbo principal, resultando na voz passiva e nos tempos compostos, respectivamente (VILLALVA, 1994). 
Beard (1995) destaca que os verbos auxiliares devem ser vistos sincronicamente como elementos gramaticais, como morfemas lexicalizados que desempenham um papel funcional na gramática. Assim, no caso das construções passivas com o verbo auxiliar "ser" ("être", "to be") e nos tempos compostos com o verbo auxiliar "ter" ("avoir", "to have"), destaca-se que estas partículas desempenham o mesmo papel de um sufixo flexional, agregando complexidade à voz no caso das passivas e especificação do aspecto no caso dos tempos compostos (MARANTZ, 1997).

A forma simples do pretérito mais-que-perfeito do indicativo do português, utilizado para especificarem-se eventos anteriores a outros eventos passados, possui uma produtividade muito baixa, sendo utilizado praticamente somente na literatura (e.g., ele tive[ra] cantado). Essa forma herdada do latim possui o sufixo [-ra] representando o passado anterior a outro passado. Entretanto, utiliza-se normalmente o tempo composto formado pelo verbo auxiliar conjugado no pretérito imperfeito do indicativo seguido do particípio passado (e.g., eu tinha cantado) (MARGOT'TI, 2008). Neste caso, o verbo auxiliar conjugado no imperfeito do indicativo agrega especificidade aspectual e temporal de um evento imperfeito anterior a outro evento no passado. $\mathrm{O}$ francês e o inglês não possuem a forma simples deste tempo verbal, contudo, igualmente ao português, o francês utiliza o tempo composto plus-que-parfait formado pelos verbos auxiliares "avoir" ou "être" conjugados no imparfait seguidos do participe passé (e.g., elle avait chanté, elle était arrivée 'ela tinha cantado', 'ela tinha chegado') (ESTIVALET; MARGOTTI, 2014). Já o inglês utiliza o tempo composto past perfect formado pelo verbo auxiliar "to have" conjugado no simple past seguido do past participle (e.g., she had played 'ela tinha tocado') (BUENO, 1996; MURPHY, 1990).

Nesse sentido, pode-se considerar que os tempos compostos fazem parte do paradigma de conjugação verbal, cada qual com seu nome específico (e.g., pretérito perfeito composto, pretérito imperfeito composto, etc.), sendo caracterizados pela utilização de verbos auxiliares específicos ("ter" e "ser"). Esses verbos auxiliares desempenham um papel funcional, atribuindo complexidade temporal e aspectual ao predicado com o tempo composto (BEARD, 1995). De forma bastante semelhante, mas menos restrita, as locuções verbais nascem da necessidade de expressão de predicados complexos, especialmente em relação ao aspecto verbal (ROCHA, 1999). 
Assim, as locuções verbais utilizam uma variedade de verbos auxiliares para especificar os aspectos perfeito, imperfeito e contínuo, relativos aos tempos passado, presente e futuro (TOURATIER, 1996).

Portanto, os tempos compostos fazem parte da conjugação do quadro verbal de cada língua, desempenhando um papel gramatical específico e paradigmático, assim como os demais tempos simples de cada verbo. Já as locuções verbais são construções predicativas mais livres e criativas que fazem o uso de diferentes formas verbais independentes - tempos simples e formas compostas - para indicar maior complexidade na especificidade aspectual e na relatividade temporal da sentença (CHOMSKY, 1993; CELCE-MURCIA; LARSEN-FREEMAN, 1999). Alternativamente, Ali (1964) argumenta que a descrição dos tempos compostos no quadro de conjugações não se justifica, sendo criada artificialmente pelos gramáticos, o que acaba se tornando um hábito disseminado nas gramáticas normativas. Contudo, o autor ressalta que os tempos compostos podem ser considerados distintos de outros tempos simples, assim como de outras sequências verbais, no que diz respeito à sua capacidade específica de modular o aspecto temporal. Ele ainda argumenta que nem diacronicamente é possível justificar-se tal distinção e que os tempos compostos não devem ser considerados juntos aos tempos simples por se tratarem de locuções verbais sistemáticas.

Portanto, as locuções verbais desempenham um papel fundamental na utilização e modulação aspectual e temporal na linguagem, pois possuem a função gramatical de modificarem através da combinação de formas verbais flexionadas o aspecto e relativizar o tempo do verbo principal apresentado na forma nominal (FARACO; MOURA, 1999). Logo, as locuções verbais formadas pelos tempos compostos com o verbo auxiliar "ter" indicam realização perfeita até o presente ou até determinado momento do pretérito ou futuro (e.g., ele tinha estudado, ele tem estudado, ele terá estudado). Fica claro que as locuções verbais permitem modular entre o aspecto perfectivo, imperfectivo e progressivo, mas também relativizar o tempo das ações e descrever eventos simultâneos em sentenças complexas. No inglês e no francês, os tempos compostos são tempos verbais estabelecidos no quadro de conjugações do sistema verbal, sendo incluídos nas gramáticas descritivas e manuais de ensino dessas línguas (MURPHY, 1990; GIRARDET; CRIDLIG, 2004; BESCHERELLE, 2006a). 
Entretanto, nem todas as sequências verbais com verbos auxiliares exprimem modulação aspectual do predicado. A combinação do verbo auxiliar "ir" ("aller", "to will") com o infinitivo (e.g., eu vou viajar, je vais voyager, I will travel), classificada como futuro próximo, não apresenta modulação aspectual, mas temporal, exprimindo um evento futuro próximo e apresentando a especificidade de restrição ou relativização no tempo (DUBOIS, 1967; PALMER, 1974; CUNHA; CINTRA, 1985). Assim, a utilização do futuro próximo, apesar de muitas vezes aplicada no lugar do futuro simples, pode ser contrastada com este último; o futuro próximo indica um evento futuro próximo e não absolutamente certo, enquanto o futuro simples indica um futuro indeterminado e certo (GIRARDET; CRIDLIG, 2004). Estas sequências não são consideradas tempos compostos, mas apenas locuções verbais, pois não apresentam uma modulação clara de aspecto. Beard (1995) observa que, enquanto algumas línguas apresentam o futuro como um sufixo concatenado ao verbo, como no caso do português e do francês (e.g., eu viajarei, je voyagerai), outras línguas fazem o uso de verbos auxiliares para tal função, como o inglês (e.g., I will travel). Todavia, a necessidade e a possibilidade de explorarem-se diferentes sentidos específicos através da combinação de partículas gramaticais, como os verbos auxiliares, fazem com que ambas as formas de futuro existam, mas com diferentes significações em contextos específicos.

Fica claro que os tempos compostos com o verbo "ter" são tempos verbais específicos que modulam o aspecto do predicado; diferentemente, as locuções verbais não necessariamente modulam o aspecto e são combinações indeterminadas de verbos com a capacidade de exprimir um predicado complexo. Logo, independente da tradição gramatical, a divisão entre tempos compostos e locuções verbais é caracterizada, por um lado, em função da funcionalidade e da regularidade na modulação aspectual dos tempos compostos e, por outro lado, em função da liberdade de complexidade predicativa das locuções verbais (VILLALVA, 1994). Enfim, abandonando-se as diferentes definições de tempo composto e locução verbal, podem-se considerar simplesmente as perífrases verbais como sequências verbais complexas que têm como objetivo realizar modulações aspectuais, temporais e modais impossíveis de serem expressas através da utilização de tempos verbais simples. Assim, essas modulações somente 
podem ser realizadas através da combinação de noções gramaticais desempenhadas pelos verbos auxiliares e as formas verbais nominais (BEARD, 1995). Ainda, podem-se utilizar preposições e advérbios específicos para a expressão de predicados verbais complexos.

Em relação às locuções verbais, elas podem ser caracterizadas de acordo a três critérios principais: funcional, semântico e histórico (ALI, 1964). Ao mesmo tempo em que esses critérios se sobrepõem, eles também se diferenciam quando se tenta entender a utilização dos verbos auxiliares nas diferentes línguas e quando se compara às suas diferentes utilizações nessas línguas. De forma alternativa, a partir das características intrínsecas à significação do papel que os verbos exercem na oração, pode-se caracterizá-los em verbos nocionais e verbos relacionais (ALMEIDA, 1963). Verbos nocionais são empregados com função predicativa: jogar, comer, dormir etc., enquanto verbos relacionais são combinados com outros verbos ou adjetivos para constituir um predicado complexo: ter, ser, ir, verbos modais etc. A partir desse critério, pode-se considerar os verbos auxiliares nas três línguas em questão como verbos relacionais, pois estes verbos são sistematicamente combinados com outros verbos nocionais, em geral, com formas verbais nominais, para a criação e expressão de predicados complexos, principalmente no que diz respeito à modulação do aspecto e à relativização do tempo. Os verbos nocionais são utilizados em suas conjugações simples e não sofrem influência do complemento predicativo. Quando utilizados como verbos principais nas formas nominais, são agregados de complexidade aspectual e relatividade temporal definidas pelos verbos auxiliares. Enfim, compete ao verbo expressar o predicado, termo essencial a toda proposição, mais do que as conjugações simples, as perífrases verbais permitem a modulação do aspecto através dos tempos compostos e as locuções verbais permitem uma maior complexidade ao predicado de forma livre e criativa (ARNAULD, LANCELOT, 1992; VILLALVA, 1994).

Para decidir quando os verbos formam locuções verbais, Ali (1963, p. 61) aconselha utilizar o critério semântico: "usado ao lado dos verbos andar, ir e vir, o gerúndio terá o sentido de simultaneidade, formando oração à parte, caso nos ditos verbos prevaleça o sentido de locomoção. Se, pelo contrário, servirem apenas para denotar duração e atualidade da ação expressa pelo gerúndio, passam a funcionar como verbos auxiliares de uma conjugação 
composta". Por exemplo, "eu vou pensando ao trabalho" seria o primeiro caso, formando uma locução verbal com o sentido de locomoção; diferentemente, "eu vou caminhando a pé" seria o segundo caso, com uma conjugação composta. Já conforme Pontes (1979, p. 21), a locução verbal é uma "combinação de vocábulos semanticamente equivalente a um único vocábulo, ou seja, uma combinação de semantema (verbo principal) e morfema (verbos auxiliares)". Essa definição aproxima-se da proposta de Beard (1995), onde os verbos auxiliares são partículas funcionais gramaticais que agem sobre o predicado e o verbo principal (MARANTZ, 1997). Portanto, paralelo aos critérios históricos diacrônicos e semânticos, observa-se que o critério morfossintático estabelece relações entre os constituintes do predicado verbal complexo. Essas relações são hierarquizadas e subordinadas, de forma que a ordem linear dos elementos coordenados define as relações entre os constituintes no predicado verbal complexo. Em relação aos critérios sintáticos das locuções verbais, Almeida (1963, p. 271) destaca:

se um ente pode ser expresso por mais de um nome, constituindo assim uma locução substantiva, se também um adjetivo pode constituir-se de mais de uma palavra, obtendo-se desta forma uma locução adjetiva, pode igualmente uma ação ser expressa por mais de um verbo, daí resultando a locução verbal, ou, por outras palavras, expressa-se a ação por meio de uma frase, por meio de uma locução, por meio de um ou mais verbos. Sempre que tal acontece, o último dos verbos é que expressa a verdadeira ação, a ação que se quer manifestar, e o outro (ou os outros, quando a locução é constituída de mais de dois verbos) indica o modo, o tempo, a pessoa ou numa palavra, a idéia acessória da ação.

Dessa forma, Almeida (1963) resume as principais observações e conclusões realizadas sobre as locuções verbais. $\mathrm{O}$ autor propõe que as locuções verbais podem ser divididas em quatro grupos principais: (1) locuções verbais que indicam passividade com o verbo auxiliar "ser" e o particípio passado do verbo principal (e.g., eu fui pago, je fus payé/j'ai étépayé, I was paid); (2) locuções verbais que indicam linguagem projetada com os verbos auxiliares "ter" e "haver" e o infinitivo impessoal do verbo principal 
ligados pela preposição "de" (e.g., eu tenho de pagar, il me faut payer, I have to pay); (3) locuções verbais que indicam continuidade, frequência ou reiteração de ação com o verbo auxiliar "estar" seguido do gerúndio ou do infinitivo impessoal do verbo principal através da preposição “a” (e.g., eu estou pagando/eu estou a pagar, je paie/je suis en train de payer, I am paying); e (4) locuções verbais que indicam começo ou desenvolvimento gradual de ação com os verbos auxiliares "ir" e "vir" junto do gerúndio do verbo principal para exprimir começo ou desenvolvimento gradual da ação (e.g., o trem vai saindo/o trem vem chegando, le train part/le train arrive, the train is leaving/ the train is arriving), ou com o infinitivo no caso do verbo "ir" formando o futuro próximo (e.g., eu vou pagar, je vais payer, I will pay) e com o verbo "vir" através da preposição "de", formando o passado recente (e.g., eu venho de pagar, je viens de payer, I just have paid) (ALMEIDA, 1963). A partir do que foi discutido sobre os tempos compostos e as locuções verbais no português, no francês e no inglês, observa-se, nos exemplos acima, que não há uma correspondência perfeita entre essas três línguas, mas diferentes formas de representar o sentido no predicado complexo. Essas diferenças são determinadas em função (a) da morfologia verbal, (b) dos verbos auxiliares, (c) dos tempos compostos, (d) das locuções verbais, (e) de preposições ou advérbios e (f) de construções equivalentes.

Sendo assim, no caso (1) acima, enquanto o português e o inglês apresentam a mesma construção, o francês utiliza o passé composé com o verbo auxiliar "être" seguido do particípio passado do verbo principal, sendo que a construção com o passé simple poderia ser utilizada literalmente ou formalmente. Em (2), o português e o inglês também possuem a mesma construção, enquanto o francês emprega uma construção com o verbo "falloir" 'ter que', destaca-se que o francês também poderia utilizar uma construção com o verbo modal “devoir" 'dever' (e.g., je dois payer). Logo, as construções em português e inglês em (2) podem ser classificadas como construções modais com o verbo "ter" (to have) seguidas de preposição e do verbo principal no infinitivo. No caso (3), o português e o inglês possuem novamente construções iguais com o gerúndio, enquanto o francês utiliza simplesmente o présent para indicar eventos em curso de desenvolvimento, ou ainda a construção "être en train de" 'estar prestes a' para indicar eventos que estão na eminência de acontecer. Em (4), no primeiro exemplo, as três 
línguas possuem construções diferentes, enquanto o português forma locuções verbais com os verbos “ir" e "vir", o francês utiliza simplesmente o présenttambém poderia utilizar a construção "être en train de" - e o inglês utiliza o present continuous. No segundo exemplo de (4), as três línguas possuem a mesma construção. Porém, no terceiro exemplo de (4), o português e o francês possuem a mesma construção com o verbo "vir" ("venir") seguido da preposição "de" e do infinitivo, formando o passado recente (BESCHERELLE, 2006b), enquanto o inglês não possui esta construção e emprega o advérbio " just" 'apenas' para expressar eventos que acabaram de acontecer. Enfim, fica claro que não existem critérios objetivos que definem os tempos compostos e as locuções verbais nas três línguas, pelo contrário, cada língua possui autonomia, especificidade e diversidade na construção de predicados complexos verbais de acordo com seu próprio desenvolvimento e necessidade (BAKER, 1984; CHOMSKY, 1993).

Apesar de não abordados neste trabalho, os verbos modais utilizados correntemente no português, francês e inglês poderiam ser considerados uma segunda classe de verbos auxiliares para a formação de predicados verbais complexos, realizando modulação no modo (BEARD, 1995). Por exemplo, no português, os verbos modais "poder", "querer" e "dever", equivalentes aos verbos modais do francês "pouvoir", "vouloir" e "devoir" e equivalentes aos verbos modais do inglês "to can", "to want" e "to must", respectivamente, são utilizados para se modular o modo de um evento (e.g., eu posso ajudar, je peux aider, I can help; eu quero ajudar, je veux aider, I want to help; eu devo ajudar, je dois aider, I must help).

Diferentemente do português e do francês, o inglês possui o verbo auxiliar "to do" com um comportamento e uma utilização bastante distintos dos demais verbos auxiliares descritos até aqui, mas de extrema importância para as sentenças negativas e interrogativas no inglês (PALMER, 1974). Emprega-se o verbo "to do" nas sentenças negativas e interrogativas que não são formadas com outros verbos auxiliares (e.g., he loves NY, he does not love NY, does he love NY? 'ele (não) ama NY(?)'). Destaca-se que o verbo "to do", quando utilizado como verbo principal, apresenta o sentido nocional "to make" 'fazer', mas quando utilizado como verbo auxiliar, não possui nenhum significado e nem provoca nenhuma alteração aspectual, como o verbo "to have" provoca (e.g., I do not sing 'eu não canto', do you sing? 'tu cantas?'; I have not 
singed 'eu não cantei', have you singed? 'tu cantaste?'). No que diz respeito à morfologia verbal, enquanto as línguas latinas possuem diversos sufixos modo-temporais e número-pessoais, o inglês possui apenas três sufixos: [ed] para o passado, [-s] para a terceira pessoa do presente e [-ing] para a forma progressiva (e.g., I play 'eu jogo', he play[s] 'ele joga', I play[ed] 'eu joguei', I am play [ing] 'eu estou jogando' (MARANTZ, 1997). Assim, podese fazer uma distinção objetiva entre o aspecto finitivo e não finitivo do inglês em relação à sua forma e sua conjugação. A primeira forma dos verbos, ou seja, as conjugações simples formadas apenas a partir do lexema de base verbal são sempre finitas (play, plays); já a segunda forma dos verbos, isto é, as formas compostas com os verbos auxiliares seguido de alguma das formas nominais do verbo principal, são não finitas (to play, played, plaing) (PALMER, 1974).

Em relação aos verbos auxiliares do francês, os tempos compostos devem ser conjugados com os verbos auxiliares "avoir" ou "être". Com o verbo auxiliar "avoir", conjugam-se os tempos compostos de todos os verbos transitivos e da maioria dos verbos intransitivos; nestes casos, o participe passé nunca concorda com o sujeito da sentença, mas concorda em gênero e número com o complemento objeto direto da proposição quando ele é anterior ao verbo principal (e.g., les filles, il les a aimées 'as meninas, ele as adorou) (EMONDS, 1978). Com o verbo auxiliar "être", conjugam-se os tempos compostos de verbos intransitivos específicos: (a) verbos que exprimem movimento: "aller" 'ir', "venir" 'vir', "arriver" 'chegar', "partir" 'partir', "entrer" 'entrar', "sortir" 'sair', “monter" 'subir', “descendre" 'descer', "passer" 'passar' e "tourner" 'girar', (b) verbos que exprimem estado ou mudança de estado: “décéder" 'falecer', "devenir" 'transformar', "éclore" 'eclodir', "rester" 'ficar', "naître" 'nascer' e "mourir" 'morrer', (c) verbos reflexivos e pronominais: "s'appeler" 'chamar-se', "se laver" 'lavar-se' etc., (d) todos os verbos derivados desses verbos e (e) todos os tempos da voz passiva. Ainda, há verbos que são conjugados com o verbo auxiliar "avoir" quando são transitivos e com o verbo auxiliar "être" quando são intransitivos (e.g., je suis monté par l'ascenceur 'eu subi de elevador', j'ai monté les boites 'eu subi as caixas') (CORRÊE; STEINBERG, 1968). 


\section{Auxiliares e Complexidade Predicativa}

Nesse trabalho, realizou-se primeiramente a descrição dos conceitos de verbo auxiliar, tempos compostos, locuções verbais e conjugações perifrásticas; em seguida, discutiu-se a utilização e o emprego dos verbos auxiliares e das locuções verbais no português, no francês e no inglês; finalmente, compararam-se o desenvolvimento desses conceitos e as realizações dos verbos auxiliares nas diferentes línguas, a fim de se observar e melhor se compreender a função gramatical modular dos verbos auxiliares nos tempos compostos e locuções verbais (BEARD, 1995).

Observou-se que os verbos auxiliares desempenham um papel fundamental nos tempos compostos, mas principalmente na criação de locução verbais com predicados complexos, tendo como principal objetivo relativizar e modular as noções de tempo e aspecto das proposições (PONTES, 1973). Verificou-se que este artifício das línguas abordadas realiza uma função gramatical na subespecificação e complexidade do sintagma tempo-aspectual da frase (BAKER, 1984). Enfim, as principais semelhanças e diferenças entre os verbos auxiliares do português, do francês e do inglês se fazem aparentes e perceptíveis a partir a análise paralela de suas construções, aplicações, funcionamento e utilizações nessas línguas.

Sendo assim, os verbos auxiliares, tempos compostos, locuções verbais e conjugações perifrásticas foram discutidos e analisados comparativamente através de conceitos, citações, exemplos e observações. Uma série de fenômenos secundários também foram destacados, assim como os pontos em que há ou não acordo entre os gramáticos e as línguas. Portanto, novos estudos teóricos, comparativos e experimentais devem ser realizados para uma maior compreensão do desenvolvimento diacrônico e da utilização sincrônica dos verbos auxiliares nas diferentes línguas (BYBEE, 1995).

Finalmente, esse estudo aprofundou o conhecimento dos verbos auxiliares como elementos funcionais especiais das gramáticas do português, do francês e do inglês, proporcionando uma melhor compreensão da necessidade de utilização de sentenças complexas, principalmente no que diz respeito à modulação aspectual entre eventos finitos e não finitos. Assim, as conjugações compostas são largamente utilizadas como um paradigma de utilização dos verbos. Ainda, a criatividade e a recursividade das locuções 
verbais com verbos auxiliares permitem uma maior complexidade na expressão de predicados complexos de acordo com a necessidade do locutor (CHOMSKY, 1993). Portanto, fica clara a singularidade de cada uma das línguas na utilização dessas estruturas, assim como um tronco comum de seu funcionamento.

\section{Agradecimentos}

Gostaria de agradecer ao Conselho Nacional de Desenvolvimento Científico e Tecnológico (CNPq, Processo: 238186/2012-1) pelo financiamento durante a realização desta pesquisa. Agradeço enormemente a dois pareceristas anônimos da revista Signum: Estudos da Linguagem, pelas valiosas observações e sugestões realizadas na versão anterior do texto. Agradeço, também, à editora desta revista, pela atenção, seriedade e profissionalismo durante as fases de submissão, avaliação e edição do artigo. Enfim, agradeço a Marco Rocha pelas valiosas discussões e provocações acerca dos verbos auxiliares.

\section{Anexo A}

\begin{tabular}{|c|c|c|c|c|c|c|c|}
\hline \multicolumn{5}{|c|}{ PORTUGUÊS } & \multicolumn{3}{|c|}{ FRANCÊS } \\
\hline \multicolumn{5}{|c|}{ MODO INDICATIVO } & \multicolumn{3}{|c|}{ INDICATIF } \\
\hline \multicolumn{5}{|l|}{ Presente } & \multicolumn{3}{|l|}{ Présent } \\
\hline$\overline{\mathrm{eu}}$ & tenho & hei & sou & estou & $j^{\prime}$ & ai & suis \\
\hline tu & tens & hás & és & estás & tu & as & es \\
\hline ele/ela & tem & hás & é & está & il/elle/o & & est \\
\hline nós & temos & havemos & somos & estamos & nous & avons & sommes \\
\hline vós & tendes & haveis & sois & estais & vous & avez & êtes \\
\hline eles/elas & têm & hão & são & estão & ils/elles & ont & sont \\
\hline
\end{tabular}




\begin{tabular}{|c|c|c|c|c|c|c|c|}
\hline \multicolumn{5}{|c|}{ Pretérito imperfeito } & \multicolumn{3}{|c|}{ Imparfait } \\
\hline$\overline{\mathrm{eu}}$ & tinha & havia & era & estava & $j^{\prime}$ & avais & étais \\
\hline tu & tinhas & havias & eras & estavas & tu & avais & étais \\
\hline ele/ela & tinha & havia & era & estava & il/elle/o & avait & était \\
\hline nós & tínhamos & havíamos & éramos & estávamos & nous & avions & étions \\
\hline vós & tínheis & havíeis & éreis & estais & vous & aviez & étiez \\
\hline eles/elas & tinham & haviam & eram & estão & ils/elles & avaient & étaient \\
\hline \multicolumn{5}{|c|}{ Pretérito perfeito } & \multicolumn{3}{|c|}{ Passé simple } \\
\hline $\mathrm{eu}$ & tive & houve & fui & estive & $j^{\prime}$ & eus & fus \\
\hline tu & tiveste & houveste & foste & estiveste & tu & eus & fus \\
\hline ele/ela & teve & houve & foi & esteve & il/elle/o & eut & fut \\
\hline nós & tivemos & houvemos & fomos & estivemos & nous & eûmes & fûmes \\
\hline vós & tivestes & houvestes & fostes & estivestes & vous & eûtes & fûtes \\
\hline eles/elas & tiveram & houveram & foram & estiveram & ils/elles & eurent & furent \\
\hline \multicolumn{5}{|c|}{ Pretérito mais-que-perfeito } & \multicolumn{3}{|c|}{ Plus-que-parfait } \\
\hline $\mathrm{eu}$ & tivera & houvera & fora & estivera & $j^{\prime}$ & avais eu & avais été \\
\hline tu & tiveras & houveras & foras & estiveras & tu & avais eu & avais été \\
\hline ele/ela & tivera & houvera & fora & estivera & \multicolumn{2}{|c|}{ il/elle/on avait eu } & avait été \\
\hline nós & tivéramos & souvéramos & fôramos & estivéramos & nous & avions eu & avions été \\
\hline vós & tivéreis & houvéreis & fôreis & estivéreis & vous & aviez eu & aviez été \\
\hline eles/elas & tiveram & houveram & foram & estiveram & ils/elles & avaient eu & I avaient été \\
\hline \multicolumn{5}{|c|}{ Futuro do presente } & \multicolumn{3}{|c|}{ Futur simple } \\
\hline$\overline{\mathrm{eu}}$ & terei & havereis & serei & estarei & $j^{\prime}$ & aurai & serai \\
\hline tu & terás & haverás & serás & estarás & tu & auras & seras \\
\hline ele/ela & terá & haverás & será & estarás & \multicolumn{2}{|c|}{ il/elle/on aura } & sera \\
\hline nós & teremos & haveremos & seremos & estaremos & nous & aurons & serons \\
\hline vós & tereis & havereis & sereis & estareis & vous & aurez & serez \\
\hline eles/elas & terão & haverão & serão & estarão & ils/elles & auront & seront \\
\hline
\end{tabular}




\begin{tabular}{|c|c|c|c|c|c|c|c|}
\hline \multicolumn{4}{|c|}{ Futuro do pretérito } & \multicolumn{4}{|c|}{ Futur antérieur } \\
\hline $\mathrm{eu}$ & teria & haveria & seria & estaria & $j^{\prime}$ & aurai eu & aurai été \\
\hline tu & terias & haverias & serias & estarias & tu & auras eu a & auras été \\
\hline ele/ela & teria & haveria & seria & estaria & il/elle/on & aura eu & aura été \\
\hline nós & teríamos & haveríamos & seríamos & estaríamos 1 & nous & aurons eu a & aurons été \\
\hline vós & teríeis & haveríeis & seríeis & estaríeis & vous & aurez eu a & aurez été \\
\hline eles/elas & teriam & haveriam & seriam & estariam & ils/elles & auront eu $\mathrm{a}$ & auront été \\
\hline \multicolumn{5}{|c|}{ MODO SUBJUNTIVO } & \multicolumn{3}{|c|}{ SUBJONCTIF } \\
\hline \multicolumn{5}{|l|}{ Presente } & \multicolumn{3}{|l|}{ Présent } \\
\hline $\mathrm{eu}$ & tenha & haja & seja & esteja & $j^{\prime}$ & aie & sois \\
\hline tu & tenhas & hajas & sejas & estjas & tu & aies & sois \\
\hline ele/ela & tenha & haja & seja & esteja & il/elle/o & on ait & soit \\
\hline nós & tenhamos & hajamos & sejamos & estejamos & nous & ayons & soyons \\
\hline vós & tenhais & hajais & sejais & estejais & vous & ayez & soyes \\
\hline eles/elas & tenham & hajam & sejam & estejam & ils/elles & aient & soyent \\
\hline \multicolumn{5}{|c|}{ Pretérito imperfeito } & \multicolumn{3}{|l|}{ Imparfait } \\
\hline$\overline{\mathrm{eu}}$ & tivesse & houvesse & fosse & estivesse & $j^{\prime}$ & eusse & fusse \\
\hline tu & tivesses & houvesses & fosses & estivesses & tu & eusses & fusses \\
\hline ele/ela & tivesse & houvesse & fosse & estivesse & \multicolumn{2}{|c|}{ il/elle/on eût } & fût \\
\hline nós & tivéssemo & s houvéssem & tos fôssemo & s estivéssemo & os nous & eussions & s fussions \\
\hline vós & tivésseis & houvésseis & fôsseis & estivésseis & vous & eussiez & fussiez \\
\hline eles/elas & tivessem & houvessem & fossem & estivessem & ils/elles & eussent & fussent \\
\hline \multicolumn{8}{|l|}{ Futuro } \\
\hline$\overline{\mathrm{eu}}$ & tiver & houver & for & estiver & & & \\
\hline tu & tiveres & houveres & fores & estiveres & & & \\
\hline ele & tiver & houver & for & estiver & & & \\
\hline nós & tivermos & houvermos & formos & estivermos & & & \\
\hline vós & tiverdes & houverdes & fordes & estiverdes & & & \\
\hline eles & tiverem & houverem & forem & estiverem & & & \\
\hline
\end{tabular}


INGLÊS

\begin{tabular}{|c|c|c|c|c|c|c|}
\hline \multicolumn{4}{|c|}{ Simple present } & \multicolumn{3}{|c|}{ Present / Past continuous } \\
\hline $\mathrm{I}$ & have & $\mathrm{am}$ & do & $\mathrm{I}$ & $\mathrm{am} / \mathrm{was}$ & + gerund \\
\hline you & have & are & do & you & are/were & + gerund \\
\hline he/she/it & has & is & does & he/she/it & is/was & + gerund \\
\hline we & have & are & do & we & are/were & + gerund \\
\hline you & have & are & do & you & are/were & + gerund \\
\hline they & have & are & do & they & are/were & + gerund \\
\hline \multicolumn{4}{|c|}{ Simple past } & \multicolumn{3}{|c|}{ Present / Past perfect } \\
\hline $\bar{I}$ & had & was & did & I & have/had & + past participle \\
\hline you & had & were & did & you & have/had & + past participle \\
\hline he/she/it & had & was & did & he/she/it & has/had & + past participle \\
\hline we & had & were & did & we & have/had & + past participle \\
\hline you & had & were & did & you & have/had & + past participle \\
\hline they & had & were & did & they & have/had & + past participle \\
\hline \multicolumn{4}{|c|}{ Future I / Conditional I } & \multicolumn{3}{|c|}{ Future II / Conditional II } \\
\hline$\overline{\mathrm{I}}$ & \multicolumn{2}{|c|}{ will/would } & \multicolumn{2}{|c|}{+ infinitive I } & will/would have & + past participle \\
\hline you & \multicolumn{2}{|c|}{ will/would } & \multicolumn{2}{|c|}{+ infinitive you } & will/would have & + past participle \\
\hline he/she/it & \multicolumn{2}{|c|}{ will/would } & \multicolumn{2}{|c|}{ + infinitive he/she/it } & will/would have & + past participle \\
\hline we & \multicolumn{2}{|c|}{ will/would } & \multicolumn{2}{|c|}{+ infinitive we } & will/would have & + past participle \\
\hline you & \multicolumn{2}{|c|}{ will/would } & \multicolumn{2}{|c|}{+ infinitive you } & will/would have & + past participle \\
\hline they & \multicolumn{2}{|c|}{ will/would } & \multicolumn{2}{|c|}{+ infinitive they } & will/would have & + past participle \\
\hline
\end{tabular}




\section{Referências}

ALI, M. S. Gramática secundária e gramática histórica da língua portuguesa. 3. ed. Brasília: Editora Universidade de Brasília, 1964.

ALMEIDA, N. M. de. Gramática metódica da língua latina. 15. ed. São Paulo: Saraiva, 1963.

ANDRÉ, H. A. de. Gramática ilustrada. 4. ed. São Paulo: Moderna, 1990.

ARNAULD, A.; LANCELOT, C. Gramática de Port-Royal. Tradução Bruno Fregni Basseto e Henrique Graciano Murachco. São Paulo: Martins Fontes, 1992 [1660].

BAKER, M. The mirror principle and morphosyntactic explanation.

Linguistic Inquiry, v. 16, n. 3, p. 373-415, 1984.

BAYLON, C.; FABRE, P. Grammaire systematique de la langue française. 3. ed. France: Éditions Nathan, 1995.

BEARD, R. Lexeme-morpheme base morphology: a general theory of inflection and word formation. Albany: State University of New York Press, 1995. BESCHERELLE. La conjugasion. Paris: Hatier, 2006a.

BESCHERELLE. La grammaire. Paris: Hatier, 2006b.

BONET, E. Agreement in two steps (at least). In: MATUSHANSKY, O.; MARANTZ, A. (Ed.). Distributed morphology today: morphemes for Morris Halle. Cambridge: The MIT Press, 2013. p. 167-184.

BUENO, F. da S. Minidicionário inglês - português, português - inglês. São Paulo: FTD, 1996.

BYBEE, J. Regular morphology and the lexicon. Language and Cognitive Processes, v. 10, n. 5, p. 425-455, 1995.

CELCE-MURCIA, M.; LARSEN-FREEMAN, D. The grammar book. 2. ed. Boston: Heinle \& Heinle, 1999. 
CHOMSKY, A. N. A minimalist program for linguistic theory. In: HALE, K.; KEYSER, S. J. (Ed.). The view from building 20: essays in Linguistics in honor of Sylvain Bromberger. Cambridge: The MIT Press, 1993. p. 1-52.

CORRÊEA, R. A.; STEINBERG, S. H. Gramática da língua francesa. Rio de Janeiro: FENAME, 1968.

CUNHA, C.; CINTRA, L. F. L. Nova gramática do português contemporâneo.

2. ed. Rio de Janeiro: Nova Fronteira, 1985.

DUBOIS, J. Grammaire structurale du français: le verbe. Paris: Larousse, 1967.

EMONDS, J. The complex V'-V in French. Linguistic Inquiry, v. 9, n. 2, p. 151-175, 1978.

ESTIVALET, G. L.; MARGOT'TI, F. W. Diálogos entre a flexão verbal do português e do francês. Estudos da Lingu(agem), v. 12, n. 2, p. 31-49, 2014. (Dialogues entre la flexion verbale du Portugais et du Français).

FARACO, C. E.; MOURA, F. M. de. Gramática. 12. ed. São Paulo: Ática, 1999.

FERNANDES, F.; LUFT, C. P.; GUIMARÃES, F. M. Dicionário brasileiro Globo. 29. ed. São Paulo: Globo, 1993.

GIRARDET, J.; CRIDLIG, J.-M. Panorama de la langue française 1. Sejer: CLE International, 2004.

INFANTE, U. Textos: leituras e escritas. São Paulo: Scipione, 2004.

HOUAISS, A.; VILLAR, M. D. S. Dicionário Houaiss da língua potuguesa. Rio de Janeiro: Objetiva, 2009.

MARANTZ, A. No escape from syntax: don't try morphological analysis in the privacy of your own lexicon. In: DIMITRIADIS, A.; SIEGEL, L. et al. Proceedings of the 21st Annual Penn Linguistics Colloquium, Penn Working Papers in Linguistics, p. 201-225, 1997.

MARGOTTI, F. W. Morfologia do português. Florianópolis: LLV/CCE/ UFSC, 2008. 
MURPHY, R. Essential grammar in use. Great Britain: Cambridge University Press, 1990.

PALMER, F. R. The English Verb. Great Britain: Longman, 1974.

PONTES, E. Verbos auxiliares em português. Petrópolis: Vozes, 1973.

RICHARDS, J. C. Interchange - Student's Book 2. 3. ed. United Kingdom: Cambridge University Press, 2005.

ROCHA, L. C. D. A. Estruturas morfológicas do português.

Belo Horizonte: Editora UFMG, 1999.

TOURATIER, C. Le système verbale français (description morphologique et morphémique). Paris: Masson and Armand Colin, 1996.

VILLALVA, A. Estruturas morfológicas: unidades e hierarquias nas palavras do português. Lisboa, 1994.

Recebido em: 11/05/2017 Aceito em: 28/10/2017 